\title{
RECOMENDAÇÕES DE MARX \\ PARA ENTENDER E RESOLVER UMA CRISE DO BRASIL (UMA HOMENAGEM)
}

\author{
MARX'S RECOMMENDATIONS \\ TO UNDERSTAND AND RESOLVE A CRISIS IN BRAZIL \\ (A TRIBUTE)
}

Ivandro da Costa Sales ${ }^{1}$

1. É necessário e urgente tentar identificar os objetivos, as estratégias, os desejos, os sonhos, as táticas, vitórias e derrotas dos grupos econômicos importantes. São grupos econômicos importantes: os trabalhadores masculinos, femininos, autônomos, empregados, desempregados, sub-empregados, trabalhador coletivo, trabalhador universal e também os empresários grandes e pequenos, nacionais e internacionais. Cuidado! É comum esquecer que os trabalhadores são grupos econômicos importantes. Lembrar que ser trabalhador é uma honra, enquanto ser mercadoria e nem conseguir se vender como força de trabalho, é uma desgraça.

2. A história é o resultado das parcerias, alianças, oposições e antagonismo de interesses, desejos, sonhos e direitos (econômicos, políticos, culturais, afetivos, religiosos, estéticos...) desses grupos econômicos importantes. Os interesses econômicos, além de importantes, nunca podem deixar de ser pesquisados.

3. Conhecer as organizações econômicas, políticas, culturais e religiosas dos grupos econômicos dominantes e dos grupos explorados e subalternizados. Quais dessas

\footnotetext{
1 Doutor em Serviço Social pela Universidade Federal de Pernambuco- UFPE. Mestre em Sociologia do Desenvolvimento- Université Catholique de Louvain. Licença em Sociologia. Orientação: Sociologia do Desenvolvimento- Université Catholique de Louvain. e-mail: ivandrosales@hotmail.com
} 
organizações dispõem de mais e melhores meios materiais e financeiros? Quem tem assessores mais competentes? (Ter bons assessores é essencial).

4. Assessores são estudiosos, que (com ou sem diploma, oriundos da própria classe ou de outras classes e categorias), se dedicam a pensar, expressar e organizar os interesses dos grupos a quem eles devem prestar um serviço, em busca permanente de soluções para seus problemas. Os grandes grupos econômicos dominantes não dispensam os serviços desses bons e competentes auxiliares.

5. Qualquer proposta que não inclua a socialização dos meios de produção e também o planejamento da produção e distribuição individual e coletiva do produto, é uma proposta reformista que, quando muito, faz alguns retoques na ordem capitalista atual, ordem que é a grande responsável pela exploração e dominação que se quer acabar.

6. Socialização não se identifica com a atual estatização. É uma "associação de pessoas livres". As estatais no capitalismo nunca foram, nem são, nem serão do povo. São instituições do capital nacional e internacional. É também oportuno não identificar governamental com público. As organizações governamentais podem muito bem ser fundamentalmente um serviço a interesses privados.

7. A cada dia os capitalistas precisam mais do governo (e sempre são atendidos) para definir e "aperfeiçoar" as leis trabalhistas, previdenciárias, fiscais, cambiais, penais... Eles, os capitalistas, nunca dispensaram o apoio definitivo do governo. Cuidado, portanto, ao falar superficialmente em liberalismo e neoliberalismo.

8. É preciso e urgente tentar resgatar e reforçar a função estatal das organizações trabalhistas e populares da sociedade civil, função estatal que poderia assim ser resumida: definir, fiscalizar e executar, (em parceria com o governo), as políticas públicas. Infelizmente essa função tão importante foi usurpada e monopolizada pelo governo, tido erroneamente, durante muito tempo e ainda agora, como único responsável pela gestão da sociedade e do "Bem Comum". 
9. O fim da exploração econômica e dominação social será conduzida por organizações autônomas, compostas e dirigidas por representantes das diversas organizações populares. Algumas dessas organizações são destinadas à realização de objetivos específicos (econômicos, políticos, culturais, afetivos, religiosos, estéticos...). Outras terão como objetivo político, não a realização de objetivos específicos, mas a gestão da sociedade com vistas ao fim da exploração e da dominação em todas as práticas sociais.

10. Os representantes das organizações trabalhistas e populares que perseguem fins específicos (econômicos, políticos, culturais, religiosos, estéticos...), como os sindicatos, associações e tantas outras formas associativas, não devem esquecer que a consecução de seus objetivos não pode deixar de estar conectada com a construção de uma sociedade sem exploração e dominação. Quem se contenta só com a realização de objetivos específicos, consegue vitórias importantes, mas fica pelo caminho, e é só reformista.

11. Organização não significa colar uma grelha na realidade, ou impor pacotes vindo dos cartórios eleitorais, ou copiar formas de outros tempos e outros contextos. Organização não é imposição de fôrmas. É, sim, criação de formas adequadas para discutir e resolver problemas. Para a solução de cada problema devem, então, ser buscadas formas oriundas do aperfeiçoamento do que, em cada situação, é ou já foi vivido como sucesso ou fracasso.

12. Que formas organizativas criar para acabar a exploração e a dominação na agricultura e nas empresas nacionais? E para planejar a produção e distribuição de bens? E para gerir todo o excedente que surgirá necessariamente de uma economia planejada e que use tecnologias avançadas? A esse respeito convém saber que o excedente que não for apropriado privativamente, como se dá no capitalismo, não é mais-valia ou exploração. E deve se transformar em fundo de reserva para saúde, segurança, bem estar, infraestrutura e tudo mais de bom.

13. Não acontecerá nada de importante e eficaz para a mudança da atual ordem capitalista, se não se conseguir enfrentar as corporações internacionais e transnacionais. Como seria esse enfrentamento urgente e necessário? Será que tem, ou daria para se ter 
representantes dos trabalhadores e dos movimentos populares em organismos internacionais como Fundo Monetário Internacional, Organização Mundial do Comércio e outras do mesmo nível? Urge pensar.

14. Como transformar a pequena produção individual e os pequenos negócios individuais ou coletivos, pouco produtivos, em grande produção e grandes negócios, geridos democraticamente, "por homens e mulheres livres e associados"?

15. A gestão de uma sociedade sem exploração e dominação inclui a criação um modo específico e democrático de administrar os interesses e direitos da sociedade, modo esse que administrará a instauração de um modo coletivo e democrático de produzir e distribuir bens e serviços.

16. Não alimentar, entretanto, a ilusão de que a gestão do fim da exploração e dominação seja feita pelas instituições atuais da democracia burguesa. A "Democracia" no capitalismo, sob qualquer de suas formas, (representativa, parlamentarista, monarquia representativa etc.) é, e não pode deixar de ser, um serviço à manutenção e desenvolvimento da ordem capitalista.

17. No período de transição do atual modo capitalista para um outro modo mais democrático e planejado de produzir e distribuir bens e de gerir a sociedade, é de toda a conveniência que se elejam representantes competentes para ocupar espaços nas instituições da atual ordem burguesa. Atenção! Que lá estejam para, com firmeza, e sem alianças com adversários, (a não ser alianças pontuais e passageiras), discutir, exigir, pressionar e fazer conhecidas suas reivindicações. E preparados para as muitas derrotas, sabendo, entretanto, que sua atuação firme e competente pode minar o poder dos exploradores e reforçar um outro modo de gestão da sociedade.

18. O novo modo de gestão da sociedade não precisará de personalidades salvadoras e não terá profissionais da política. Os representantes serão eleitos para, num prazo definido, cumprir determinadas tarefas, e serem substituídos, se não conseguirem realizá-las. Algumas das instituições da velha ordem serão mantidas e aperfeiçoadas, outras serão extintas. 


\section{Revista \\ Debates Insubmissos}

19. Que se faça uma diferença ente Reforma e Revolução. A Reforma faz retoques na ordem estabelecida. A Revolução é uma mudança radical no modo de produzir bens e serviços e no modo de gerir a sociedade.

20. Uma Reforma pode ser feita em pouco tempo. Uma Revolução Social exige muita paciência e tempo para mudança das estruturas e das pessoas. Uma Revolução exige clareza e profundidade sobre as possibilidades objetivas e subjetivas das mudanças, sobre os fundamentos, objetivos, estratégias e táticas da ação revolucionária. Não basta querer ou esperar que as mudanças caiam do céu. É loucura ter objetivos para os quais não existam os meios adequados para consegui-los.

21. É provável que, dada a complexidade das sociedades atuais, com suas múltiplas, complexas e diferenciadas instituições e formas organizacionais, (suportes da ordem vigente), a luta pelo fim da exploração e da dominação se dê pela ocupação de espaços, em vez de tomada de poder pela força das armas. Aliás, mesmo na ocupação de espaços, só haveria uso da violência armada, em última instância e em resposta à violência dos adversários.

22. Nada impede, entretanto, e talvez seja até aconselhável, que, a partir de vivências existentes em qualquer lugar da humanidade, se pensem em formas alternativas de produção e distribuição de bens e de gestão da sociedade.

\section{QUE MENSAGEM, ATUALMENTE, NOS MANDARIA MARX?}

Continua existindo uma relação tensa e intensa entre forças produtivas e relações de produção. E essa contradição dá o rumo da história.

Cada estágio do desenvolvimento das forças produtivas (força de trabalho, conhecimentos, instrumentos de produção, qualidade das matérias primas) exige uma atualização das relações de produção e das estruturas políticas, jurídicas, ideológicas. 


\section{Revista \\ Debates Insubmissos}

A grande tensão entre forças produtivas e ralações de produção nas sociedades capitalistas é que enquanto se amplia a dimensão social da produção, aumenta, paralelamente, a dimensão privada do consumo de bens e serviços e da gestão da sociedade.

Depois da dimensão individual, profissional e de classe, se chegou à dimensão humana. Classe é uma diminuição da dimensão humana. A grande meta é o fim da sociedade de classes e a criação de uma sociedade de homens e mulheres livres e que conheçam os fundamentos de sua atuação.

Os antagonismos, contradições, alianças e parcerias entre os diferentes grupos econômicos, políticos e culturais criaram sempre vários tipos de gestão da sociedade e concepções de mundo adequados à manutenção de privilégios dos grupos dominantes, mas geraram, igualmente, contradições que permitiram a continuação da luta pela afirmação dos interesses e direitos dos grupos subalternizados.

$\mathrm{Na}$ fase capitalista da nossa história, tivemos o artesanato, a manufatura, a grande indústria e agora as finanças e cada uma delas com um tipo de cooperação e um tipo de trabalhador. Passamos da cooperação simples à cooperação mundial e planetária. Do trabalhador autônomo ao trabalhador geral, universal, planetário. Não existe produto da ação humana que não seja resultado da cooperação de diferentes conhecimentos, diferentes países, diferentes continentes.

Os antagonismos de classe também se modificam. Durante um tempo os grupos dominantes eram os capitalistas e os grupos subalternizados eram os operários, camponeses e pequena burguesia. $\mathrm{Na}$ fase atual do capitalismo, os grupos financeiros exercem sua dominação sobre os trabalhadores, pequenos e grandes capitalistas rurais e industriais e também sobre todos os governos nacionais. Ampliou-se, então, o arco de possíveis alianças.

Das fases do artesanato, manufatura e grande indústria conhecemos as relações se produção e modos de gestão. Que novas relações de produção e formas de gestão estão pedindo para nascer no estágio atual da luta de classes da dominação do capital financeiro? 
O novo coronavirus está ajudando a revelar a dimensão planetária do mundo. Mostra também o caráter destrutivo da livre iniciativa, do lucro individual. Parece igualmente claro que o sucesso do combate a epidemia é bem maior onde se teve algum controle e algum planejamento.

Talvez a lógica dos direitos deva ser substituída por dimensões humanas e ambientais. Em vez, então, de "nenhum direito a menos", coloque-se como perspectiva "nenhuma dimensão a menos".

Iguais na produção, no consumo, no exercício do poder, perante a lei, diante de Deus, revelação do novo vírus!

\section{SOBRE A NOSSA ATUAÇÃO NESSE TEMPO DE PANDEMIA}

Contribuir para a formação de pessoas "sabidas" e fortes. São "sabidas" as pessoas não preconceituosas e que têm argumentos fortes para o que falam e praticam. São fortes as que definam e redefinam permanentemente, e de forma coletiva, os seus objetivos e os meios de consegui-los

Incentivar pessoas sabidas e fortes a criar espaços de debates e decisões coletivas e, se lhes for prazeroso, a ocupar espaços em organizações existentes, na condição, entretanto, de nos manter inflexíveis em nossos princípios, e democráticos na aceitação de formas diferentes de atuação.

\section{REFERÊNCIAS}

GRAMSCI, Antônio. Cadernos do Cárcere. Edição de Carlos Nelson COUTINHO com Marco Aurélio NOGUEIRA e Luiz Sérgio HENRIQUES. Rio de Janeiro: Civilização Brasileira. Volume 3. Caderno 13. 2000. 
LÊNIN, V. I. Estado e a Revolução. São Paulo: Hucitec. 1978.

MARX, Karl. A Guerra Civil na França. São Paulo: Boitempo editorial. 2011.

MARX, Karl. O Dezoito Brumário de Luís Bonaparte. São Paulo: Edições Sociais. 1977.

MARX, Karl. As lutas de classe na França. São Paulo: Edições Sociais. 1977.

MARX, Karl. O Capital. Crítica da Economia Política. Rio de Janeiro: Civilização Brasileira. 2006

SALES, da Costa Ivandro. Os desafios da gestão Democrática da sociedade. Em diálogo com Gramsci. Recife e Fortaleza: Editora da UFPE e Edições UVA. 2006. $2^{a}$ edição.

SALES, da Costa Ivandro. Saber o Poder: elementos de teoria e metodologia. Observatório dos Movimentos Sociais. Centro Acadêmico do Agreste, Universidade Federal de Pernambuco. Recife: Comunigraf Editora. 2010.

SALES, da Costa Ivandro. Junho de 2013 no Brasil: A farsa perdeu a graça. E agora? O público e o privado. Revista do Programa de Pós-graduação em Sociologia da Universidade Estadual do Ceará. № 21. Fortaleza: Jan/junho. 2013.

Submetido em: 09/04/2020

Aprovado em: 13/04/2020 